\title{
ASPECTOS JURÍDICOS SOBRE A CONTROVERTIDA MULTA NAS AÇÕES TARDIAS DE INVENTÁRIO
}

\author{
Augusto Passamani Bufulin ${ }^{1}$ \\ Miryã Bregonci da Cunha Braz
}

\section{RESUMO:}

Segundo as legislações estaduais, o requerimento do inventário após determinado prazo enseja multa aplicável sobre o imposto de transmissão. Entretanto, é possível notar no ordenamento jurídico brasileiro diversos prazos para abertura do inventário, inclusive nos próprios Códigos Civil e de Processo Civil. Assim, mediante pesquisa bibliográfica e método indutivo, objetiva-se examinar as disposições legais sobre a abertura do inventário e bem como analisar se há prazo mínimo a ser observado para que os estados-federativos exijam multa pelo requerimento tardio de inventário.

PALAVRAS-CHAVE: Direito de sucessão; Processo sucessório; Inventário; Multa; Prazo.

\section{LEGAL ASPECTS OF THE CONTROVERSIAL FINE IN THE DELAYED INVENTORY LAWSUITS IN THE BRAZILIAN SUCCESSION PROCESS}

\begin{abstract}
:
According to brazilians state laws, requesting the inventory in the succession process after a certain period entails a fine applicable on the transmission tax. However, it is possible to note in the Brazilian legal system several deadlines for opening the inventory, including in the Brazilian Civil and Civil Procedure Codes themselves. Thus, through bibliographic research and inductive method, the objective is to examine the legal provisions on the opening of the inventory and to analyze whether there is a minimum period to be observed for the federal states to demand a fine for the late inventory request.
\end{abstract}

KEYWORDS: Succession Rights; Succession Process; Inventory; Fine; Term.

\section{INTRODUÇÃO}

Com a morte, considera-se aberta a sucessão do falecido e todo o seu patrimônio é transferido automaticamente para todos os seus herdeiros, formando uma universalidade de bens, pelo fenômeno da saisine. Para que seja feita a individualização dos bens destinando-os a cada um dos herdeiros, é necessário que seja realizado, inicialmente, o levantamento de

\footnotetext{
${ }^{1}$ Professor Adjunto do Departamento de Direito da UFES. Juiz de Direito (TJES). Mestre e Doutor em Direito Civil pela PUC/SP. Membro pesquisador do grupo "Desafios do Processo". contatoapb@ protonmail.com

${ }^{2}$ Mestranda em Direito Processual pela UFES. Especialista em Direito Civil e Processo Civil (FGV). Bolsista CAPES/DS. Professora voluntária (UFES). Membro pesquisador do grupo "Desafios do Processo". mbdacunha@ hotmail.com.
} 
todos os bens, direitos e deveres de titularidade do de cujus por meio do inventário, em uma de suas especiais: inventário judicial, inventário extrajudicial, arrolamento sumário ou arrolamento comum.

Após a listagem de todo o patrimônio do de cujus, é realizada a repartição dos bens aos herdeiros pelo procedimento denominado partilha. Com isto, ocorrerá a transferência do patrimônio, que compunha o espólio, para os herdeiros individualmente considerados.

Em virtude de diversos fatores, desde emocionais até financeiros, o início do procedimento para levantamento do patrimônio pode ser postergado ao longo do tempo pelos herdeiros. Desta forma, é possível encontrar tanto no Código Civil quanto no Código de Processo Civil um prazo máximo para que seja realizado o requerimento deste procedimento. Além disso, exercendo sua competência constitucional, os estados federativos instituíram multa aplicável ao contribuinte em virtude de abertura tardia do procedimento.

Ocorre que, em cada uma dessas legislações, é possível encontrar prazos distintos para abertura do inventário. O Código de Processo Civil de 2015, diferente de seu antecessor, estipula o prazo de dois meses (artigo 983), enquanto é possível encontrar no Código Civil o prazo de trinta dias (artigo 1.796). Há ainda um terceiro prazo de sessenta dias, previsto em decretos estaduais como do estado do Espírito Santo e São Paulo, e, até mesmo, de cento e vinte dias, como previsto na legislação estadual do Mato Grosso. Deste modo, pergunta-se: qual é o prazo máximo para abertura do inventário sem cominação de multa?

Assim, diante deste problema, o presente artigo tem como objetivo examinar as disposições legais sobre a abertura do inventário, principalmente no que concerne à delimitação do prazo de abertura do inventário e sua forma de contagem. Busca-se, ainda, analisar se há algum lapso temporal que deva ser observado pelos estados federativos para aplicação de multa por requerimento tardio. Para atingir tais objetivos, foi utilizado o Método Indutivo de pesquisa, tendo por base a utilização de pesquisa bibliográfica.

Considerando que a contagem de prazos em dias e meses é realizada de maneiras distintas, bem como a definição e composição da norma jurídica, faz-se uma análise do histórico do prazo de abertura nos Códigos Civil e de Processo Civil desde 1916, além de proceder com uma análise aprofundada do destinatário da norma federal consubstanciada nestes diplomas, especificamente no artigo 611 do Código de Processo Civil atualmente vigente. Expõe-se, ao fim, a possibilidade de aplicação de multa pelos estados federativos por 
conta de requerimento tardio da abertura do inventário e analisa-se se há algum prazo mínimo, máximo ou único, que deva ser respeitado por todas as legislações estaduais.

Para fins didáticos e de concisão, adotaremos no presente trabalho apenas o termo "inventário", mas as conclusões e considerações aqui tecidas quanto ao prazo de requerimento de seu início e a implicação de multa pelo seu requerimento tardio aplicam-se ao inventário judicial, inventário extrajudicial, arrolamento sumário e arrolamento comum. Registra-se ainda que é possível encontrar ao fim do trabalho anexo contendo as disposições legais dos Códigos Civil e de Processo Civil desde 1916 sobre prazos para abertura do inventário.

\section{CONSIDERAÇÕES INICIAIS}

Antes de adentrar ao mérito da discussão, é de suma importância analisar temas que são fundamentais para atingir a finalidade deste artigo. Deste modo, faz-se necessário tecer considerações prazos em geral, especificamente no que concerne à sua qualificação e forma de contagem. Além disso, importante abordar em linhas gerais o conceito de norma jurídica, sua composição e seus destinatários, estabelecendo premissas de grande relevância para análise do ponto principal deste trabalho.

\subsection{Prazo em dias e em meses}

É importante a distinção entre prazos em meses e prazos em dias, pois a forma de contagem destes é totalmente distinta, de modo que um mês não pode ser lido como trinta dias e vice-versa. A opção do legislador em utilizar ora o termo "mês/meses", ora o termo “dia/dias" para qualificar prazos deve ser levada em conta para o cômputo do lapso temporal ao qual a norma se refere.

Em se tratando de prazos materiais, sua contagem é regulamentada pelo Código Civil de modo que os prazos em dias devem ser contados dia a dia, excluído o dia do começo, e incluído o do vencimento (Artigo 132, Código Civil de 2002), enquanto os prazos de meses expiram no dia de igual número do de início, ou no imediato, se faltar exata correspondência (Artigo 132, §3º , Código Civil de 2002).

Exemplificando, suponha que o legislador preveja que determinados atos $\left(\mathrm{A}^{?}\right)$ devam ser realizados no prazo máximo $\left(\mathrm{P}^{\text {? }}\right)$, cujo termo inicial é a data de determinado fato $\left(\mathrm{F}^{\text {? }}\right)$. 
Partindo dos termos iniciais e dos prazos fictícios abaixo, facilmente podemos constatar que a adoção de determinado prazo em dias e em meses pode gerar datas distintas como termo final do ato:

Tabela 1 - Casos hipotéticos para visualização da diferença da contagem de prazos em dia e em meses

\begin{tabular}{|c|c|c|}
\hline $\begin{array}{c}\text { Data de ocorrência do fato } \\
\text { (termo inicial) }\end{array}$ & Prazo & $\begin{array}{l}\text { Data final para realização do ato } \\
\text { (termo final) }\end{array}$ \\
\hline \multirow{2}{*}{$F^{A}=29 / 12 / 2018$} & $\mathrm{P}^{1}=60$ dias & $\mathrm{A}^{1}=27 / 02 / 2019$ \\
\hline & $\mathrm{P}^{2}=2$ meses & $A^{2}=01 / 03 / 2019$ \\
\hline \multirow{2}{*}{$F^{B}=01 / 02 / 2019$} & $\mathrm{P}^{3}=60$ dias & $\mathrm{A}^{3}=02 / 04 / 2019$ \\
\hline & $\mathrm{P}^{4}=2$ meses & $A^{4}=01 / 04 / 2019$ \\
\hline \multirow{2}{*}{$F^{C}=01 / 07 / 2019$} & $\mathrm{P}^{5}=60$ dias & $A^{5}=30 / 08 / 2019$ \\
\hline & $\mathrm{P}^{6}=2$ meses & $A^{6}=01 / 09 / 2019$ \\
\hline
\end{tabular}

Fonte: Elaboração própria.

FIGURA 1 - Contagem de prazo com termo inicial em 29/12/2018 (FA)

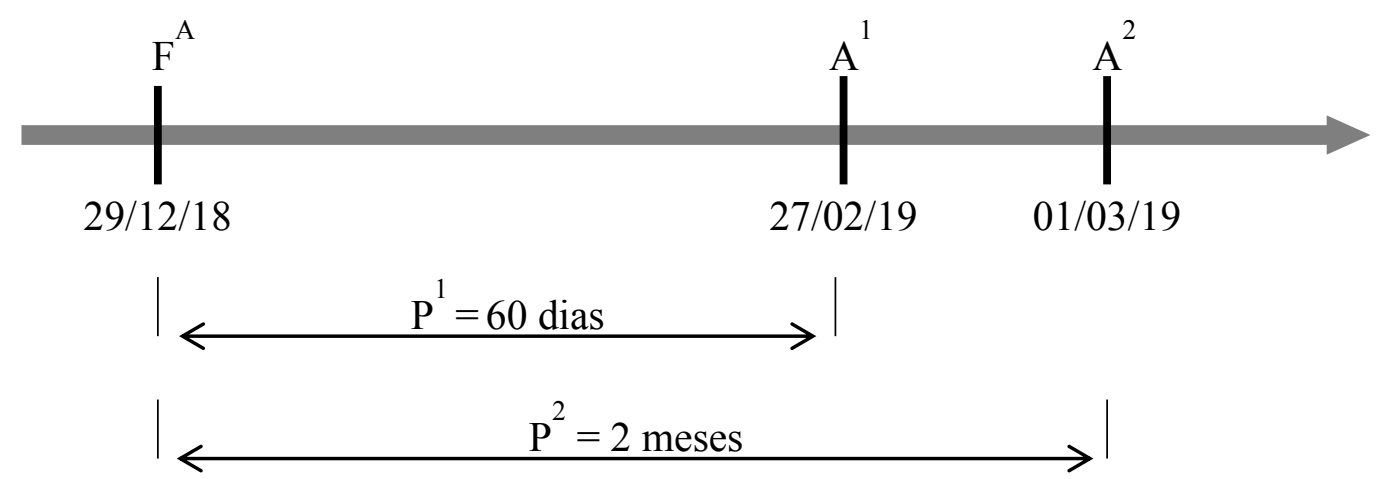

Fonte: Elaboração própria a partir das informações constantes da Tabela 1. 
FIGURA 2 - Contagem de prazo com termo inicial em 01/02/2019 $\left(\mathrm{F}^{\mathrm{B}}\right)$


Fonte: Elaboração própria a partir das informações constantes da Tabela 1.

FIGURA 3 - Contagem de prazo com termo inicial em 01/07/2019 $\left(\mathrm{F}^{\mathrm{C}}\right)$
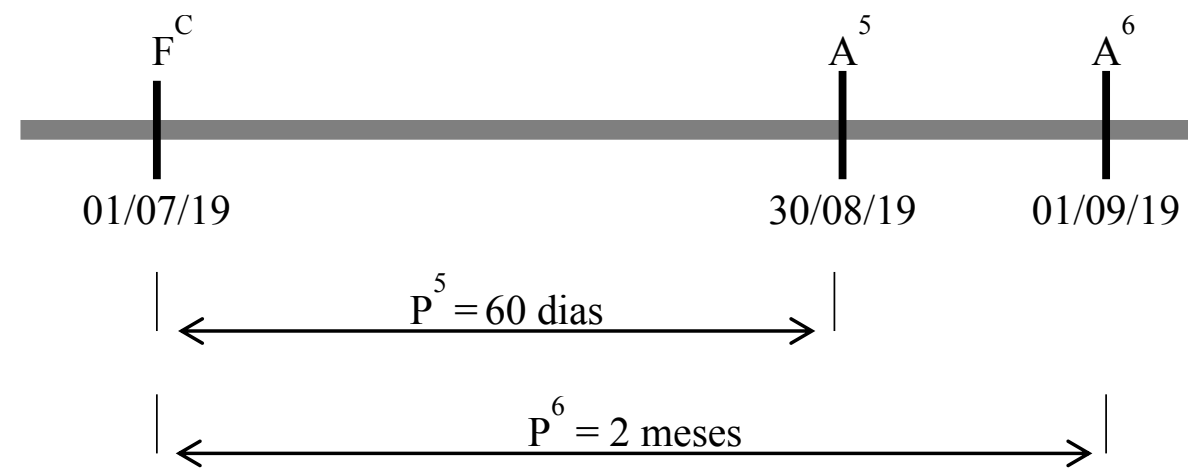

Fonte: Elaboração própria a partir das informações constantes da Tabela 1.

Assim, caso o indivíduo realize o ato $\mathrm{A}^{1}$ no dia 28/02/2019, este será intempestivo, na medida em que, por ser contado em dias corridos, o prazo $\mathrm{P}^{1}$ já havia transcorrido. Note-se que, somente in concretu, é possível apurar se o prazo em dias ou em meses se consumará primeiro. Portanto, é de suma importância a determinação da qualificação exata do prazo instituído para a prática de um ato, principalmente se o desrespeito a este prazo permitir que seja atribuída determinada penalidade ao indivíduo.

\subsection{A norma jurídica e sua composição}

Norma jurídica não corresponde, necessariamente, ao texto literal dos dispositivos legais. Em verdade, norma jurídica é a significação colhida da leitura dos textos do direito 
positivo (CARVALHO, 2004, p. 8), ou seja, é fruto de um esquema de interpretação realizado pelo indivíduo quando da leitura dos textos legais (SANTI, 1999, p. 35). Deste modo, não é o texto escrito (o artigo, o parágrafo ou o inciso de uma lei) que se qualifica como norma jurídica, mas as "expressões irredutíveis ${ }^{3}$ de manifestação do deôntico" dele extraído (do texto escrito). (CARVALHO, 2015, ebook).

Para a significação do texto positivo ser elencada como norma jurídica, é necessário que sua análise seja realizada com base no todo em qual está inserida. Noberto Bobbio, citado por Santi, ensina que as normas jurídicas nunca existem isoladamente, mas sempre em um contexto de normas com relações particulares entre si (SANTI, 1999, p. 35).

Há na norma jurídica sempre um sujeito (destinatário da ordem), a previsão de um ato (que deve ser realizado) e uma ocasião (momento em que o ato deve ser realizado) (NINO, 2003, p. 71). Além disso, toda norma jurídica apresenta idêntica estrutura hipotéticocondicional, na medida em que associa, num nexo de causalidade jurídica (imputação), a descrição de um fato de possível ocorrência no mundo objetivo (hipótese) a uma relação deôntica (consequência ou tese).

Da leitura de Eurico Santi e Lourival Vilanova, extrai-se que a hipótese, também denominada pressuposto, é a parte da norma que tem função descrever situação de possível ocorrência no mundo; é o fato jurídico recortado sobre o suporte fático. Já a tese, ou consequente, prescreve uma relação modalizada pelo "functor relacional deôntico" num de seus três modos relacionais específicos: permitido ("está permitido"), proibido ("está proibido") ou obrigatório (“está obrigado") (SANTI, 1999, p. 36).

É sempre possível encontrar na composição da norma jurídica uma norma primária e uma norma secundária. A norma primária é a hipótese, descritora de determinada conduta, enquanto a norma secundária é tese, representada por uma relação modalizada pelo "functor relacional deôntico" num de seus três modos relacionais específicos: permitido, proibido ou obrigatório. Normativamente vinculada à hipótese, a tese tem estrutura interna de proposição prescritiva e pode ser qualificada como uma proposição relacional (ENGISCH, 1972, p. 55). Inexistindo essa composição dual na norma, ela não pode ser considerada jurídica.

\footnotetext{
${ }^{3}$ Note-se que o termo "expressões" está no plural. Isto acontece porque, de um único texto de direito positivo, é possível extrair mais de uma norma jurídica.
} 


\section{PRAZO PARA ABERTURA DO INVENTÁRIO}

Com a morte, têm-se aberta a sucessão do falecido e, desde logo, a transmissão da herança a todos os herdeiros legítimos e testamentários (Artigo 1784, Código Civil). Para que seja feita a individualização do patrimônio e direitos do de cujus, é necessário que os herdeiros realizem a abertura do inventário para que, depois de serem quitados eventuais débitos do falecido, proceda-se com a patilha dos bens.

A abertura do inventário sujeita-se a um prazo legal e material, cujo termo inicial é a data da abertura da sucessão, ou seja, a data da morte. Este prazo não é prescricional nem decadencial, de modo que sua inobservância não implica na perda do direito à herança, mas sim na imposição de multa a ser aplicada pela Fazenda, conforme será melhor analisado. “Trata-se, a toda evidência, de um prazo impróprio, também denominado prazo de preclusão fraca." (FARIAS; ROSENVALD, 2017, p. 544).

Havendo requerimento tardio de inventário, não pode o juiz julgar extinto o processo nem mesmo o tabelião se recusar a lavrar a escritura. Ademais, "Requerimento fora do prazo não implica indeferimento de abertura do inventário pelo juiz, mesmo porque se trata de procedimento obrigatório, de ser cumprido a qualquer tempo, sem prazo fatal" (OLIVEIRA,; AMORIM, 2018, p. 306). Neste sentido, Luiz Carvalho (2017, p. 879) ressalta que

\footnotetext{
"Caso haja demora demasiada ou inércia no andamento do procedimento judicial do inventário, não se admite a extinção do feito, mesmo porque há interesse, inclusive fiscal, em sua conclusão. Na prática determina-se o arquivamento e aguarda-se a provocação dos interessados para o seu prosseguimento."
}

Acontece que tanto o Código Civil quanto o Código de Processo Civil vigentes preveem prazos distintos para requerimento de inventário. Em verdade, é possível notar a antinomia com relação a este lapso temporal desde, pelo menos, a coexistência do Código Civil de 1916 e do Código de Processo Civil de $1973 .{ }^{4}$

\subsection{Antes da vigência do Código de Processo Civil de 2015}

\footnotetext{
${ }^{4}$ O presente trabalho analisa a imposição de multa pelo descumprimento do prazo de início do inventário. Deste modo, não abordaremos sobre o prazo final para que o inventário seja ultimado.
} 
Tanto o Código Civil de 1916 (BRASIL, 1916) quanto o código processual de 1939 (BRASIL, 1939) determinavam expressamente que o inventário deveria ser iniciado "dentro em um mês" a contar da abertura da sucessão. Com o advento do Código de Processo Civil de 1973 (CPC/73), o prazo passou a ser de trinta dias, ou seja, contado em dias corridos (BRASIL, 1973), o que foi mantido pelo Código Civil de 2002 (BRASIL, 2002). Entretanto, como registrado por Christiano Cassettari (2008, p. 126):

Como muitas pessoas sempre criticaram a norma, alegando que o prazo de 30 dias era insuficiente para a família, ainda comovida pela perda do ente querido e ter que se preocupar com a parte burocrática do inventário, o legislador, na lei ora comentada, entendeu por bem aumentar o referido prazo para 60 dias.

Deste modo, em 2007, a Lei $\mathrm{n}^{\mathrm{o}} 11.441 / 07^{5}$ alterou dispositivos do CPC/73, inserindo no ordenamento jurídico um novo prazo para abertura ${ }^{6}$ do inventário: sessenta dias. À época, o legislador optou por alterar apenas a redação do código processual, não se manifestando expressamente quanto a alterações na redação do Código Civil, que era de trinta dias. Com isto, “[...] o art. 1.796 do Código Civil foi derrogado, pois o prazo que lá consta foi inspirado no art. 983 do Código de Processo Civil, modificado pela Lei 11.441/2007, fazendo com que somente sua parte final ainda esteja em vigência.” (CASSETTARI, 2008, p. 126)

Por oportuno, registra-se que, embora o dispositivo do código processual refira-se somente ao inventário judicial, o prazo aplica-se a todas as espécies de inventário. Isto porque:

(...) não podemos fazer uma interpretação gramatical, analisando pura e simplesmente o texto da lei, e sim uma interpretação sistemática, examinando os outros dispositivos existentes. Assim, com o advento da Lei 11.41/2007, que abriu a possibilidade de execução de inventário extrajudicial, deveremos entender que o citado artigo estabelece o prazo para a realização judicial ou extrajudicial do inventário. (CASSETTARI, 2008, p. 126)

Portanto, embora o Código de Processo Civil de 1973 tenha sido promulgado anteriormente ao Código Civil, o dispositivo específico sobre o prazo para abertura de inventário era mais recente no diploma processual (CPC/73). Como a Lei n ${ }^{\circ} 11.441 / 2007$, que deu nova redação ao artigo 983 do Código de Processo Civil de 1973, era mais recente que o Código Civil, houve revogação tácita do artigo 1.784 do Código Civil, prevalecendo o

\footnotetext{
${ }^{5}$ Esta lei alterou dispositivos do Código de Processo Civil de 1973, possibilitando a realização de inventário, partilha, separação consensual e divórcio consensual por via administrativa.

${ }^{6}$ A partir de 2007, abandonaram-se os verbos "começar" e "iniciar" e passou-se a adotar "abrir".
} 
dispositivo do diploma processual, de modo que o prazo para abertura do inventário desde 2007 foi dilatado para sessenta dias.

\subsection{Durante a vigência do Código de Processo Civil de 2015}

Com o novo Código de Processo Civil de 2015 (BRASIL, 2015), foi dada nova redação ao dispositivo que prevê o tempo para abertura do inventário. Em que pese ter mantido o termo inicial como a data da abertura da sucessão, o novo diploma normativo processual alterou o lapso temporal para abertura do inventário, prevendo em seu artigo $611 \mathrm{o}$ prazo dois meses:

Como [o CPC/15] se trata de legislação mais recente sobrepõe-se à regra do Código Civil que previa 30 dias a partir da morte do autor da herança. Contudo, o inadimplemento não gera consequência alguma. A inércia não sujeita o omisso a qualquer sequela. O atraso só aumenta os encargos tributários, fazendo incidir multa, correção monetária e juros de mora. (DIAS, 2015, p. 567)

Embora não tenha revogado expressamente o Código Civil vigente, o Código de Processo Civil "manteve" a revogação tácita do dispositivo daquele diploma, tal como já havia sido feito por seu código processual antecessor. Ao estabelecer o prazo em meses, o legislador optou por retornar a contagem do prazo da maneira prevista no Código Civil de 1916 e no de Processo Civil de 1939, entretanto com lapso mais alargado.

Fazendo-se uma análise das previsões dos Códigos Civil e de Processo Civil desde 1916, temos que o prazo máximo para abertura do inventário em cada um deles era o seguinte:

TABELA 2 - Prazos para abertura de inventário conforme os Códigos Civil e de Processo

Civil desde 1916

\begin{tabular}{|l|c|}
\hline \multicolumn{1}{|c|}{ Diploma Normativo } & $\begin{array}{c}\text { Prazo para abertura } \\
\text { do inventário }\end{array}$ \\
\hline Código Civil de 1916 & 1 mês \\
\hline Código de Processo Civil de 1939 & 1 mês \\
\hline Código de Processo Civil de 1973 & 30 dias \\
\hline Código Civil de 2002 & 30 dias \\
\hline Código de Processo Civil de 1973 (redação de 2007) & 60 dias \\
\hline
\end{tabular}


Código de Processo Civil de 2015

2 meses

Fonte: Elaboração própria a partir de dispositivos legais dos referidos diplomas normativos.

Portanto, atualmente, vige a norma jurídica segundo a qual o inventário deve ser aberto em até dois meses, nos termos do artigo 611 do Código de Processo Civil de 2015.

Não obstante haja previsão de tempo máximo para abertura do inventário, não há no Código Civil ou no Código Processual qualquer dispositivo que impute alguma penalidade ao particular no caso de inobservância do prazo, que sequer possui natureza decadencial ou prescricional. Deste modo, nada impede que, ultrapassado dois meses da abertura da sucessão, os herdeiros procedam com a abertura do inventário.

Entretanto, o desrespeito ao prazo máximo legal para abertura do inventário pode ensejar consequências na esfera tributária, conforme analisado a seguir.

\section{POSSIBILIDADE DE OS ESTADOS FEDERATIVOS INSTITUÍREM MULTA PELO REQUERIMENTO TARDIO DO INVENTÁRIO}

Exercendo sua competência constitucional prevista no artigo 155, I, da Constituição Federal, os estados federativos brasileiros instituíram o Imposto de Transmissão Causa Mortis e Doação (ITCMD), que, dentre outras hipóteses, incide sobre a transmissão de qualquer bem ou direito havido por sucessão legítima ou testamentária. Neste caso, conforme entendimento do Superior Tribunal de Justiça, o tributo somente será exigível após o reconhecimento judicial dos direitos dos sucessores, ou seja, após a sentença que homologa a partilha ( BRASIL, 2018; BRASIL, 2019a; BRASIL, 2019b).

Em suas legislações, além de instituírem esse imposto, os Estados constituíram uma penalidade, não prevista nos Códigos Civil e de Processo Civil, que é aplicável ao contribuinte que proceder com a abertura do inventário tardiamente. Deste modo, nos termos das legislações estaduais, não sendo observado determinado prazo, será aplicada multa sobre o ITCMD, em geral de dez a vinte por cento ${ }^{7}$.

\footnotetext{
7 Registra-se que, conforme enunciado da Súmula 542 do Supremo Tribunal Federal, não há qualquer inconstitucionalidade nesta multa, in verbis: Não é inconstitucional a multa instituída pelo Estado-membro, como sanção pelo retardamento do início ou da ultimação do inventário.
} 
Não obstante o Código de Processo Civil determinar expressamente o prazo máximo para abertura do inventário, os estados federativos também incluíram na redação de suas legislações a indicação do prazo para que o herdeiro não incorra em multa. Entretanto, observa-se que, em muitos Estados, este prazo determinado pela legislação estadual é distinto do previsto pela legislação federal.

No caso do Espírito Santo, o Decreto Estadual n. 3.469-R, de 19 de dezembro de 2013, prevê no §2. ${ }^{\circ}$ de seu artigo 17 que "Quando o inventário judicial ou extrajudicial for requerido após sessenta dias da abertura da sucessão, haverá multa adicional de dez por cento do valor do imposto devido, ainda que o recolhimento tenha sido efetuado no prazo previsto neste Regulamento" (ESPÍRITO SANTO, 2013)

É de tamanha estranheza e insegurança jurídica que a lei processual indique um prazo máximo para que o particular proceda com a abertura do inventário, enquanto a legislação estadual preveja outro prazo para que este não incorra em multa pelo requerimento tardio do inventário, e que muitas vezes possa ser menor àquele previsto pelo código processual. In concretu, pode ocorrer de o herdeiro proceder com a abertura do inventário no prazo determinado pelo Código de Processo Civil, mas incorrer em multa por ultrapassar o prazo indicado na legislação estadual, ${ }^{8}$ o que se mostra desarrazoado.

Não podem os estados, sob argumento de competência para instituir e regulamentar o tributo, imputar sanção ao contribuinte que age em estrita observância à norma federal.

\section{NORMA JURÍDICA EXTRAÍDA DO ARTIGO 611 DO CÓDIGO DE PROCESSO CIVIL}

Partindo do pressuposto que toda norma jurídica possui composição dual e prescreve determinada conduta a um sujeito quando observado determinado fato e que o dispositivo vigente para determinação do prazo de abertura do inventário é o artigo 611 do Código de Processo Civil, é possível inferir que o destinatário desta norma não são os herdeiros.

Considerando que a norma é colhida a partir de uma análise sistêmica no contexto jurídico-legal que está inserida, é necessário que este dispositivo seja interpretado em

\footnotetext{
${ }^{8}$ Como demonstrado no item 2.1 .
} 
conjunto com o artigo 155, I, da Constituição Federal e com a Súmula 542 do Supremo Tribunal Federal.

A inobservância do prazo legal descrito no artigo 611 do CPC, não gera, de per si, nenhuma consequência ao herdeiro, pois, em que pese previsão do prazo de dois meses, não está prevista qualquer proibição ou obrigação direcionada a ele no caso de inobservância do prazo. "A única consequência da perda do prazo para a abertura ou conclusão do inventário é a possibilidade de cobrança de multa fiscal, instituída por cada estado da federação, dentro de sua esfera de competência legislativa." (FARIAS; ROSENVALD, 2017, p. 544)

Assim, a única proposição prescritiva deduzida é destinada ao Estado-federativo, ou, especificamente, ao legislador estadual com competência tributária para instituição e regulamentação do ITCMD, no sentido de que é proibido aos estados instituir alguma penalidade caso o inventário seja aberto no prazo legal ou que é permitido instituir a penalidade caso o inventário não seja aberto no prazo legal. "Em outras palavras, o Código de Processo Civil somente veda que os Estados cobrem qualquer tipo de multa em até 2 meses após o óbito, sem, contudo, colocar qualquer tipo de pena para quem fizer inventário depois deste prazo.” (BRUNETTI, 2016)

Neste pensar, as normas jurídicas colhidas do artigo 611 do Código de Processo Civil são: (i) se o processo de inventário e de partilha for instaurado dentro de dois meses, a contar da abertura da sucessão (proposição descritiva) ESTÁ PROIBIDO aos Estados cobrarem qualquer tipo de multa (proposição prescritiva) e (ii) se o processo de inventário e de partilha for instaurado dentro de dois meses, a contar da abertura da sucessão (proposição descritiva) ESTÁ PERMITIDO aos Estados cobrarem qualquer tipo de multa (proposição prescritiva).

\subsection{Instituição de multa pelos estados brasileiros}

Os estados, entes federativos da União, estão formalmente vinculados às normas federais. Por conseguinte, legislações estaduais devem obrigatoriamente respeitar o artigo 611 do Código de Processo Civil e, consequentemente, às normas jurídicas dele extraídas, de modo que é proibido aplicar qualquer multa ao herdeiro no caso de observância ao prazo instituído pela norma federal. Registra-se que a norma jurídica não obriga o estado a instituir a multa, de maneira que nada impede que determinado estado não aplique qualquer 
penalidade pelo requerimento tardio do inventário, o que seria de difícil constatação na prática.

Entretanto, há um prazo mínimo que deve ser respeitado pelo legislador estadual para compor a obrigatoriedade de incidência multa pelo requerimento postergado do inventário, não podendo os estados federativos impor aos contribuintes multa por suposta abertura tardia de inventário que se realizar dentro do prazo previsto no Código de Processo Civil (dois meses). ${ }^{9}$

Ocorre que é possível encontrar legislações estaduais com indicação expressa de prazo distinto, que pode ser considerado menor no caso concreto, como é o caso dos estados do Espírito Santo e de São Paulo, que preveem o prazo de sessenta dias. Conforme explorado em tópicos anteriores, pode ocorrer de, no caso concreto, o prazo de sessenta dias se exaurir anteriormente ao prazo de dois meses. Nesta hipótese, deve ser aplicado o prazo mais benéfico ao contribuinte, e que nunca será inferior a dois meses.

Registra-se, ainda, que a previsão pela legislação estadual de prazo menor para incidência da multa não retira a validade integral da norma dele extraída ${ }^{10}$. Nestes casos, o dispositivo normativo estadual deve ser lido em conjunto com as normas jurídicas às quais está vinculado. Portanto, havendo previsão de prazo menor do que o ditado pelo artigo 611 do Código de Processo Civil, a aplicação da multa não está inviabilizada, mas sim condicionada ao prazo do diploma processual.

Lado outro, é completamente possível que a legislação estadual eleja um prazo maior do que dois meses para abertura de inventário sem cominação de multa, conforme ocorre no estado do Mato Grosso, cujo prazo é de cento e vinte dias.

Deste modo, é permitido aos estados que instituam multas a serem aplicadas pelo requerimento tardio do inventário, sendo proibida a imposição de sanção caso haja respeito ao prazo de dois meses a contar da abertura da sucessão, ou seja, a multa somente poderá ser aplicada em caso de abertura do inventário após dois meses a contar da data da morte, vide previsão do diploma processual.

\footnotetext{
${ }^{9}$ Registra-se que, após o início da vigência do CPC/15, alguns estados como Pará, Alagoas e Ceará alteraram a redação de suas legislações, de modo que a multa é aplicável àquele que requerer a abertura do inventário após dois meses.

${ }^{10}$ A norma jurídica extraída das legislações estaduais será: Se o inventário for aberto fora do prazo X (hipótese) o contribuinte ESTÁ OBRIGADO a pagar a multa Y (tese).
} 


\section{CONSIDERAÇÕES FINAIS}

Embora haja previsão no Código Civil, o prazo máximo para abertura do inventário é determinado pelo artigo 611 do Código de Processo Civil, segundo o qual o início desse procedimento deve se dar em até dois meses após a abertura da sucessão do falecido. Referido prazo, que deve ser contado em meses e não em dias, não é preclusivo ou peremptório, de modo que não há vedação à abertura do inventário após o escoamento deste lapso temporal.

Paralelamente, é exigido dos herdeiros tributo incidente sobre a transmissão de bem ou direito decorrente de sucessão e, até mesmo, multa em caso de requerimento tardio de inventário. Este tributo, no caso o ITCMD, e a multa são instituídos pelos entes-federativos da União no exercício de sua competência prevista no artigo 155, I, da Constituição Federal.

Entretanto, a norma jurídica do código processual que prevê prazo máximo para abertura do inventário não é direcionada aos herdeiros, mas aos entes-federativos da União, proibindo-os de impor qualquer multa no caso de abertura de inventário dentro do prazo de dois meses.

Portanto, não há a imposição de um prazo único para requerimento de inventário, mas sim de um prazo mínimo que deve ser observado pelos Estados para que este requerimento seja considerado tardio, de modo que a multa somente poderá ser aplicada ao contribuinte no caso de abertura de inventário após o prazo de dois meses. Neste sentido, nada impede que a legislação estadual institua multa aplicável ao requerimento não realizado dentro de dois meses, ou até mesmo dentre de prazo superior, como ocorre no estado do Mato Grosso, mas nunca inferior a dois meses.

\section{REFERÊNCIAS BIBLIOGRÁFICAS}

BRASIL. Lei no 3.071 , de $1^{\circ}$ de janeiro de 1916. Código Civil dos Estados Unidos do Brasil, $1^{\circ}$ jan. 1916. Disponivel em:

<http://www.planalto.gov.br/ccivil_03/LEIS/L3071impressao.htm>. Acesso em: 20 nov. 2019. 
BRASIL. Decreto-lei n ${ }^{\circ}$ 1.608, de 18 de setembro de 1939. Código de Processo Civil, 18 set. 1939. Disponivel em: <http://www.planalto.gov.br/ccivil_03/Decreto-Lei/19371946/Del1608.htm>. Acesso em: 20 nov. 2019.

BRASIL. Lei $n^{\circ}$ 5.869, de 11 de janeiro de 1973. Institui o Código de Processo Civil, 11 jan. 1973. Disponivel em: <http://www.planalto.gov.br/ccivil_03/LEIS/L5869.htm>. Acesso em: 20 nov. 2019.

BRASIL. Lei no 10.406, de 10 de janeiro de 2002. Institui o Código Civil, 10 jan. 2002. Disponivel em: <http://www.planalto.gov.br/ccivil_03/leis/2002/110406.htm>. Acesso em: 27 abr. 2020 .

BRASIL. Lei nº 13.105, de 16 de Março de 2015. Código de Processo Civil, 16 mar. 2015. Disponivel em: <http://www.planalto.gov.br/ccivil_03/_ato2015-2018/2015/lei/113105.htm>. Acesso em: 27 abr. 2020.

BRASIL. Superior Tribunal de Justiça (Primeira Turma). Recurso Especial no 1704359/DF. Primeira Turma, Rel. Ministro Gurgel de Faria, 2 out. 2018. Disponivel em: $<$ https://ww2.stj.jus.br/processo/revista/documento/mediado/?componente=ITA\&sequencial= $1745066 \&$ num_registro $=201702717150 \&$ data $=20181002 \&$ formato=PDF $>$. Acesso em: 20 nov. 2019.

BRASIL. Superior Tribunal de Justiça (Segunda Turma). Recurso Especial no 1771623/DF. Segunda Turma, Rel. Ministro Herman Benjamin, 4 fev. 2019. Disponivel em: $<$ https://ww2.stj.jus.br/processo/revista/documento/mediado/?componente=ITA\&sequencial= $1779759 \&$ num_registro $=201801049443 \&$ data $=20190204 \&$ formato=PDF $>$. Acesso em: 20 nov. 2019.

BRASIL. Superior Tribunal de Justiça (Segunda Turma). Agravo Interno no Agravo em Recurso Especial n⿳ 1374548/DF. Segunda Turma, Relator: Ministro Mauro Campbell 
Marques, 19 fev. 2019. Disponivel em:

$<$ https://ww2.stj.jus.br/processo/revista/documento/mediado/?componente=ITA\&sequencial= $1792932 \&$ num_registro $=201802541623 \&$ data $=20190219 \&$ formato=PDF $>$. Acesso em: 20 nov. 2019.

BRUNETTI, P. H. Qual o prazo para fazer inventário? JusBrasil, 25 jul. 2016. Disponivel em: 〈https://brunetti.jusbrasil.com.br/artigos/365273693/qual-o-prazo-para-fazer-inventario>. Acesso em: 20 nov. 2019.

CARVALHO, Luiz Paulo Vieira de. Direito das Sucessões. $3^{a}$ ed. rev. atual. e ampl. São Paulo: Editora Atlas, 2017.

CARVALHO, Paulo de Barros. Curso de Direito Tributário. 16 ed. São Paulo: Saraiva, 2004.

CARVALHO, Paulo de Barros. Direito tributário: fundamentos jurídicos da incidência. 10 ed. rev. e atual. São Paulo: Saraiva, 2015, ebook.

CASSETTARI, Christiano. Separação, divórcio e inventário por escritura pública: teoria e prática. 3 ed. São Paulo: Método, 2008.

DIAS, Maria Berenice. Manual das Sucessões. $4^{\mathrm{a}}$ ed. rev. atual. e ampl. São Paulo: Editora Revista dos Tribunais, 2015.

ENGISCH, Karl. Introdução ao pensamento jurídico. Lisboa: Fundação Calouste Gulbenkian, 1972.

ESPÍRITO SANTO. Decreto n. ${ }^{\text {o } 3.469-R, ~ d e ~} 19$ de dezembro de 2013. Regulamenta o Imposto sobre Transmissão Causa Mortis e Doação de Quaisquer Bens ou Direitos (RITCMD). Disponível em:

<http://www.sefaz.es.gov.br/LegislacaoOnline/lpext.dll/InfobaseLegislacaoOnline/ritcmd/dec 3469-r.htm?fn=document-frame.htm\&f=templates\&2.0>. Acesso em: 20 nov. 2019. 
FARIAS, Cristiano Chaves de; ROSENVALD, Nelson. Curso de direito civil: sucessões. $3^{\mathrm{a}}$ ed. rev., ampl. e atual. Salvador: Ed JusPodivm, 2017.

MATO GROSSO. Lei n ${ }^{\circ}$ 7.850, de 18 de dezembro DE 2002. Dispõe sobre o Imposto sobre Transmissão Causa Mortis e Doação, de quaisquer Bens ou Direitos - ITCD. Disponível em:

<http://app1.sefaz.mt.gov.br/0325677500623408/07FA81BED2760C6B84256710004D3940/ 375B8C284530106704256C9500491DF8>. Acesso em: 20 nov. 2019.

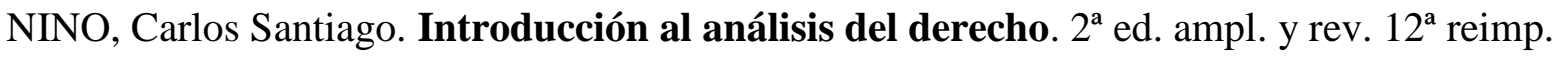
Buenos Aires: Editorial Astrea, 2003.

OLIVEIRA, Euclides; AMORIM, Sebastião. Inventário e partilha: teoria e prática. 25 ed. São Paulo: Saraiva Educação, 2018.

SANTI, Eurico Marcos Diniz de. Lançamento Tributário. São Paulo: Max Limonad, 1999. 